\title{
Intracranial Arterial Blood Flow Velocity and Brain Blood Flow during Hypocarbia and Hypercarbia in Newborn Lambs: A Validation of Range-Gated Doppler Ultrasound Flow Velocimetry
}

\author{
SVEN-ERIK SONESSON AND PETER HERIN \\ Departments of Pediatrics, Karolinska Institute, St. Göran's Children's Hospital and Karolinska Hospital, \\ Stockholm, Sweden
}

\begin{abstract}
A transfontanellar range-gated ultrasound Doppler technique for recording blood flow velocity in an artery on the base of the skull was validated in eight anesthetized newborn lambs during hypo-, normo-, and hypercarbia. Blood flow velocity was linearly related to $\mathrm{PaCO}_{2}$ from 20 to $80 \mathrm{~mm} \mathrm{Hg}$; mean blood flow velocity (Vmean) $(r=0.86, p<0.001)$, peak systolic blood flow velocity $(r=0.83, p<0.001)$, and end-diastolic blood flow velocity $(r=0.87, p<0.001)$. Vmean changed $2.0 \%$ per $\mathrm{mm} \mathrm{Hg}$ of $\mathrm{PaCO}_{2}$. A linear relationship was demonstrated between brain blood flow (BBF), as determined by the microsphere method, and $\mathrm{PaCO}_{2}(r=0.91, p<0.001)$, with BBF changing $3.6 \% / \mathrm{mm} \mathrm{Hg}$ of $\mathrm{PaCO}_{2}$. Blood flow velocity was linearly related to $\mathrm{BBF}$ in the $\mathrm{PaCO}_{2}$ range studied; Vmean $(r=0.89, p<0.001)$, peak systolic blood flow velocity $(r=0.87, p<0.001)$, and end-diastolic blood flow velocity $(r=0.87, p<0.001)$. However, Vmean predicted only approximately $55 \%$ of the change in BBF, which suggests a concomitant change in the cross-sectional area of the artery being studied. Despite this limitation, these data suggest that blood flow velocity, recorded by a transfontanellar range-gated Doppler technique from one of the two main arteries perfusing the brain, provides qualitative information on changes in BBF. (Pediatr Res 24: 423-426, 1988)
\end{abstract}

\section{Abbreviations}

Vsyst, peak systolic blood flow velocity

Vdiast, end-diastolic blood flow velocity

Vmean, mean blood flow velocity

BBF, brain blood flow

CSA, cross-sectional area

$\mathrm{S}_{\mathrm{y} / \mathrm{x}}, \mathrm{SD}$ of residuals from regression of $\mathrm{y}$ on $\mathrm{x}$

$\mathrm{Sb}_{\mathbf{y} / \mathbf{x}}, \mathrm{SD}$ of regression coefficient (b)

Several techniques have been used to evaluate BBF in the newborn infant (1). No quantitative method can be directly used and all indirect or semiquantitative techniques have some disadvantages. The Doppler technique gives information on the

Received December 16, 1987; accepted May 27, 1988.

Correspondence Sven-Erik Sonesson, Department of Pediatrics, Karolinska Hospital, S-104 01 Stockholm, Sweden.

This study was supported by the General Maternity Hospital Foundation and the Samariten Stiftelsen, Stockholm. blood flow velocity but not on the volume of the blood flow. A relationship has been demonstrated between blood flow velocity, recorded from the anterior cerebral artery, and BBF, as measured by autoradiography $(2)$ or by the microsphere method $(3,4)$, which indicates that the velocimetric technique can correctly identify the direction of changes in BBF. Although results consistent with an underestimation of BBF changes by velocity determinations have been published (4), blood flow velocity determinations, as a measurement of relative changes in $\mathrm{BBF}$, have not been completely validated.

We have recently used a transfontanellar range-gated Doppler method in infants to measure blood flow velocity in an artery on the base of the skull, i.e. the internal carotid artery (5-7). With this technique it was possible to measure blood flow velocity in a reproducible location of the largest artery perfusing the brain, where the angle between the ultrasound beam and the direction of flow is close to zero (8).

The purpose of this study in newborn lambs was to validate the range-gated Doppler technique for recording blood flow velocity in a major artery perfusing the brain as a measurement of relative changes in $\mathrm{BBF}$. This was done by using the microsphere technique as a reference standard within a wide range of $\mathrm{BBF}$ induced by hypo- and hypercarbia.

\section{MATERIALS AND METHODS}

Eight newborn lambs aged 3-17 days (mean 6 days) with a weight of 4.1-6.7 kg were studied in acute experiments during general anesthesia. The animals remained with their dams until the morning of study.

Surgical procedures. After local analgesia an infant feeding tube (Bard $5 \mathrm{Ch}$ ) was positioned in a brachial vein for injections and maintenance infusion of $5 \%$ glucose during the study. The animals were given intravenous injections of thiopental sodium $(12.5-25 \mathrm{mg} / \mathrm{kg})$, atropine $(0.5 \mathrm{mg})$, and pancuronium bromide $(0.2 \mathrm{mg} / \mathrm{kg})$. After intubation the animals were connected to an Engström UR 70 volume-limited ventilator, which delivered a gas mixture of air, oxygen, and nitrous oxide (15-35\%) during the surgical procedures and the following studies. Infant feeding tubes (Bard $5 \mathrm{Ch}$ ) with single end-holes were positioned in a brachial artery for taking reference blood samples, and in the abdominal aorta, via a femoral artery, for determinations of arterial pressure and arterial blood gases. A polyethylene catheter (Portex, ID 0.9-1.0 mm) with a single end-hole was introduced into the left ventricle via a femoral artery for the injections of microspheres. Catheter placement was verified by pressure recordings. An artificial fontanel measuring approximately $1.5 \times$ 
$1.5 \mathrm{~cm}$ was created close to the midline of the skull. The dura was left intact and the skin-flap was sutured back over the hole.

Experimental protocol. After a 60 -min stabilization period after surgery, ventilator frequency and minute volume were changed in order to achieve the $\mathrm{PaCO}_{2}$ levels of approximately $20,30,40,50$, and $>60 \mathrm{~mm} \mathrm{Hg}$. The gas mixture was adjusted to maintain normoxemia. In five animals the period of hypocarbia preceded the period of hypercarbia and in three animals the reverse was true. However, the order of reaching the $\mathrm{PaCO}_{2}$ levels within each period was not systematized. At each $\mathrm{PaCO}_{2}$ level, blood gas analyses and Doppler recordings immediately preceded and followed the BBF determinations. Doppler recordings were also made at other $\mathrm{PaCO}_{2}$ values while the ventilator was adjusted to obtain the predetermined $\mathrm{PaCO}_{2}$ levels. To achieve a steady state BBF, a period of at least $10 \mathrm{~min}$ was allowed to elapse between any change in ventilator setting and the recording of hemodynamic variables. To minimize any effect of a high or a low flow state on brain weight the animals were normoventilated for 20-30 min before being killed.

Physiological measurements. Arterial blood gases were measured using a Radiometer ABL3 blood gas analyzer. Mean arterial blood pressure was continuously recorded from the abdominal aorta, using a Gould-Statham P23 pressure transducer and a Grass 7B polygraph. Heart rate was calculated from the Doppler recording.

Intracranial arterial blood flow velocity was measured using a continuous and range-gated Doppler ultrasound velocimeter (ALFRED, Vingmed A/S, Oslo, Norway). A $5 \mathrm{MHz}, 8-\mathrm{mm}$ diameter hand-held transducer was placed with contact gel on the skin over the artificial fontanel and in the continuous mode directed toward the base of the skull. In three animals, probably because of residual air under the skin-flap, optimal quality Doppler signals could not be received until the transducer was placed directly over the dura. The instrument was switched to the range-gated mode when a strong pulsatile flow signal toward the transducer was heard and was seen on an oscilloscope. The range-gate was adjusted to receive the highest possible velocity at a maximal distance from the transducer. The mean depth setting was $3.7 \mathrm{~cm}$ (range $3.5-3.8 \mathrm{~cm}$ ), corresponding to the base of the skull (9), which suggests that the recordings were made in an artery supplying the circle of Willis with blood. The longitudinal sampling volume was $2-4 \mathrm{~mm}$, and a $100 \mathrm{~Hz}$ high-pass filter was used to reduce low frequency noise from the pulsating artery wall and the surrounding tissue. Flow velocity signals and calibration signals generated by the Doppler instrument were recorded on an Elema-Schönander Mingograph 81. An estimated cross-sectional mean flow velocity signal $(10)$ and a signal corresponding to the time average of this signal (area under the curve, Vmean), computed by the Doppler instrument, were used for all calculations. Vsyst, Vdiast, and Vmean were calculated manually from 30-40 consecutive wave-forms with the highest amplitude recorded.

$\mathrm{BBF}$ was measured with $15(3) \mu \mathrm{m}$ [mean (SD)] microspheres labeled with I-125, Cr-51, Ce-141, Sr-85, or Sc-46 (3M Co, St. Paul, MN). For each BBF determination, approximately $1.0 \times$ $10^{6}$ microspheres suspended in $1 \mathrm{ml}$ lamb plasma and Tween 80 detergent were thoroughly stirred and then injected into the left ventricle during $15-20 \mathrm{~s}$. The catheter was thereafter slowly flushed with $2 \mathrm{ml}$ of $0.9 \%$ saline. A reference blood sample from the brachial artery was withdrawn with a Sage 351 syringe pump (Sage Instruments, Inc., White Plains, NY) at a constant rate of $3 \mathrm{ml} / \mathrm{min}$, beginning $10-15 \mathrm{~s}$ before the microsphere injection and continuing for 1 min after it was completed.

After the animal was killed its brain was gently separated from the spinal cord. The brain was weighed before and after fixation in formalin. The right half of the brain was divided into a total of 20-25 samples. Radioactivity from all tissue samples and reference samples were measured in a Packard 3320 Autogamma Spectrometer (Packard Instrument Co., Downers Grove, IL). A computer program was used to correct for spillover counts from the various isotopes. $\mathrm{BBF}$ was calculated using the equation: $\mathrm{BBF}$ = counts $/ \mathrm{min}$ in brain tissue $\times$ rate of withdrawal $(3 \mathrm{ml} / \mathrm{min}) /$ counts/min in reference blood sample (11), and expressed as $\mathrm{ml} /$ $\mathrm{min} / 100 \mathrm{~g}$ wet, nonfixated tissue weight. All blood and tissue specimens contained at least 400 microspheres, usually many more, and were regarded as valid for calculation (12). However, as judged from a majority of the tissue specimens, the specific activity of the $\mathrm{Cr}-51$ isotope was too low to allow adequate evaluation with the amount of microspheres given. All the data obtained using the $\mathrm{Cr}-51$ isotope were therefore discarded.

Statistical analysis. Blood flow velocity recordings preceding microsphere injections and made at $\mathrm{PaCO}_{2}$ levels other than those used when $\mathrm{BBF}$ was determined, were correlated with $\mathrm{PaCO}_{2}$, using analysis of covariance and linear regression analysis. The averages of the blood flow velocity value before and after microsphere injection were correlated with $\mathrm{BBF}$, using linear regression analysis. Significance was tested using analysis of variance and the F-test.

\section{RESULTS}

All eight animals tolerated the surgical procedure well. Because of technical problems during the induction of anesthesia, the condition of one lamb was judged to be deteriorating and it was given epinephrine and sodium bicarbonate. The lamb recovered and, although, it thereafter remained in good condition throughout the experiment the results obtained from it were used only to compare blood flow velocity with BBF. Three other animals did not tolerate the pronounced hypercarbia $\left(\mathrm{PaCO}_{2}>65 \mathrm{~mm}\right.$ $\mathrm{Hg}$ ) induced at the end of the experimental procedure; they showed a combined acidosis $(\mathrm{pH}<7.20$, base excess $<-10$ $\mathrm{mmol} / \mathrm{liter}$ ) and a falling arterial pressure. In these three lambs, seven Doppler recordings and five BBF determinations made during a mean arterial blood pressure decrease of more than $25 \%$ of the individual control value, were excluded from the comparisons with $\mathrm{PaCO}_{2}$. The largest relative decrease in mean arterial blood pressure recorded in all other lambs was less than $15 \%$. The number of blood flow velocity recordings and BBF measurements used for analysis are shown in Table 1. Good quality Doppler recordings were obtained in all lambs. Turbulent flow was not demonstrated at any occasion.

Physiological measurements. Arterial blood gases (Table 2) showed the expected respiratory alkalosis and acidosis. A moderate decrease in $\mathrm{PaO}_{2}$ was observed during hypoventilation but it never fell to hypoxic levels. The mean values of heart rate and mean arterial pressure (Table 2) showed no significant changes in the various $\mathrm{PaCO}_{2}$ ranges.

Doppler measurements and $\mathrm{PaCO}_{2}$. Individual linear regressions (Fig. 1) calculated from six to eight recordings in each animal (four recordings in one lamb) showed a close relationship between Vmean and $\mathrm{PaCO}_{2}$, range $r=0.96-0.99$. Slopes and intercepts varied between animals $(p<0.01)$, without relation to weight or postnatal age. Despite these statistical differences between animals, the pooled data still showed linear relationships between blood flow velocities and $\mathrm{PaCO}_{2}$; Vmean (Fig. 1), Vsyst, $\mathrm{b}=0.76(0.076)(\mathrm{cm} / \mathrm{s}) / \mathrm{mm} \mathrm{Hg}, r=0.83, p<0.001$, and Vdiast, $\mathrm{b}=0.62(0.054), r=0.87, p<0.001$.

Linear correlations were found between individual absolute changes in blood flow velocities and changes in $\mathrm{PaCO}_{2}$ from normocarbic values (37.5-42.5 mm Hg); Vmean (Fig. 2), Vsyst, $r=0.93, p<0.001$, and Vdiast, $r=0.84, p<0.001$. Regression

Table 1. Number of blood flow velocity recordings and $B B F$ determinations (n) at various $\mathrm{PaCO}_{2}$ ranges

\begin{tabular}{|c|c|c|c|c|c|}
\hline $\mathrm{PaCO}_{2}(\mathrm{~mm} \mathrm{Hg})$ & $<26$ & $26-35$ & $36-45$ & $46-55$ & $>55$ \\
\hline Doppler vs $\mathrm{PaCO}_{2}\left(N^{*}=7 ; n=45\right)$ & 7 & 9 & 13 & 8 & \\
\hline r $v s \mathrm{BBF}(N=8 ; n=32)$ & 5 & 6 & 7 & 7 & \\
\hline $\mathrm{BBF}$ vs $\mathrm{PaCO}_{2}(N=7 ; n=23)$ & 5 & 5 & 6 & 3 & \\
\hline
\end{tabular}

* No. of lambs. 
Table 2. Arterial blood gases, heart rate (HR), and mean arterial pressure (MAP) values at various Pa $\mathrm{CO}_{2}$ ranges during blood flow velocity measurements (mean and $1 S D$ )

\begin{tabular}{|c|c|c|c|c|c|}
\hline $\mathrm{PaCO}_{2}$ range $(\mathrm{mm} \mathrm{Hg})$ & $<26$ & $26-35$ & $36-45$ & $46-55$ & $>55$ \\
\hline $\mathrm{PaCO}_{2}(\mathrm{~mm} \mathrm{Hg})$ & $21.6(2.3)$ & $30.5(2.6)$ & $39.6(2.6)$ & $50.5(2.6)$ & $64.5(8.3)$ \\
\hline $\mathrm{pH}$ & $7.52(0.07)$ & $7.40(0.07)$ & $7.35(0.06)$ & $7.25(0.07)$ & $7.15(0.09)$ \\
\hline $\mathrm{PaO}_{2}(\mathrm{~mm} \mathrm{Hg})$ & $109(23)$ & $106(23)$ & $124(26)$ & $119(25)$ & $92(11)$ \\
\hline $\mathrm{SaO}_{2}(\%)$ & $98(1.1)$ & $97(1.9)$ & $98(1.1)$ & $97(1.2)$ & $93(4.1)$ \\
\hline Base excess (mmol/liter) & $-3.8(4.4)$ & $-4.4(4.1)$ & $-3.6(3.0)$ & $-5.4(4.0)$ & $-7.1(3.9)$ \\
\hline $\mathrm{HR}(\mathrm{bpm})$ & $234(12)$ & $234(25)$ & $222(27)$ & $223(29)$ & $233(33)$ \\
\hline $\mathrm{MAP}(\mathrm{mm} \mathrm{Hg})$ & $96(10)$ & $101(8)$ & $96(11)$ & $101(12)$ & $94(11)$ \\
\hline
\end{tabular}

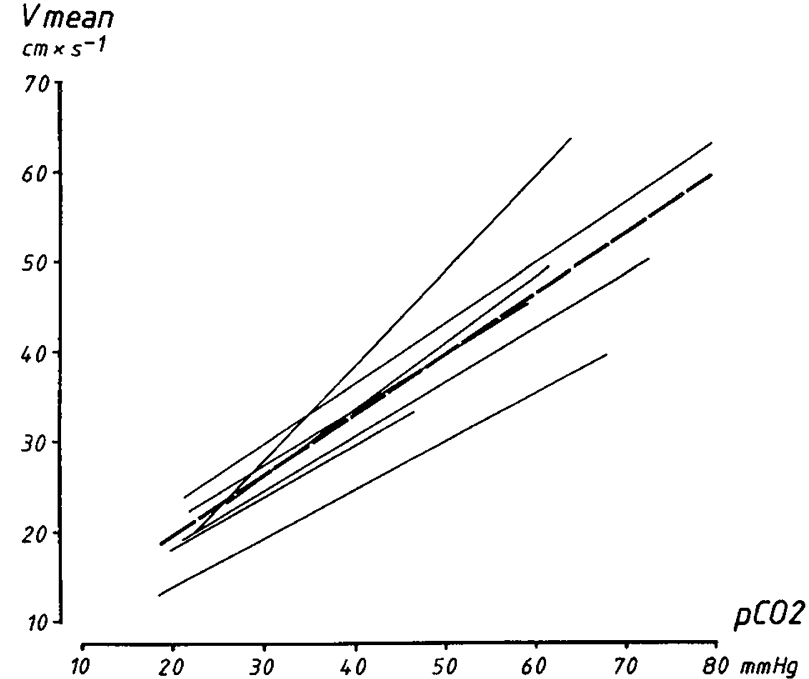

Fig. 1. Correlation between $\mathrm{Vmean}$ and $\mathrm{PaCO}_{2}(\mathrm{n}=45)$. Each animal is represented by a regression line with extension corresponding to the $\mathrm{PaCO}_{2}$ range used for analysis. The broken line is a regression line for pooled results, $\mathrm{y}=33.8+0.67(\mathrm{x}-41.4), \mathrm{S}_{\mathrm{y} / \mathrm{x}}=5.96, \mathrm{Sb}_{\mathrm{y} / \mathrm{x}}=0.061, r$ $=0.86, p<0.001$.

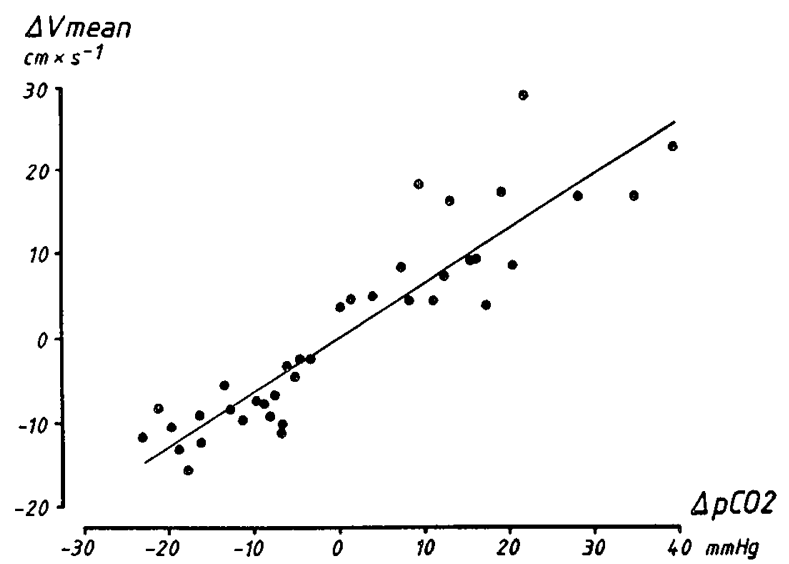

Fig. 2. Individual absolute changes in Vmean related to changes in $\mathrm{PaCO}_{2}$ from normocarbia $(37.5-42.5 \mathrm{~mm} \mathrm{Hg})$ with regression line outlined, $\mathrm{y}=0.90+0.65(\mathrm{x}-1.07), \mathrm{S}_{\mathrm{y} / \mathrm{x}}=4.45, \mathrm{Sb}_{\mathrm{y} / \mathrm{x}} 0.045, r=0.91, p<$ 0.001 .

lines of absolute changes in Vmean for hypo- and hypercarbia had similar slopes.

A linear relationship was demonstrated for individual relative changes in Vmean and changes in $\mathrm{PaCO}_{2}, \mathrm{~b}=2.0(0.13) \% / \mathrm{mm}$ $\mathrm{Hg}, r=0.92, p<0.001$. However, there was still an interindividual variation of slopes $(p<0.05)$, range $1.7-2.9 \% / \mathrm{mm} \mathrm{Hg}$.

$B B F$ and $\mathrm{PaCO}_{2}$. BBF showed a linear relationship with $\mathrm{PaCO}_{2}$ corresponding to an approximate $3.6 \%$ change in $\mathrm{BBF} / \mathrm{mm} \mathrm{Hg}$ change in $\mathrm{PaCO}_{2}$ from normocarbia (Fig. 4).

Doppler measurements and $B B F$. Linear relationships were

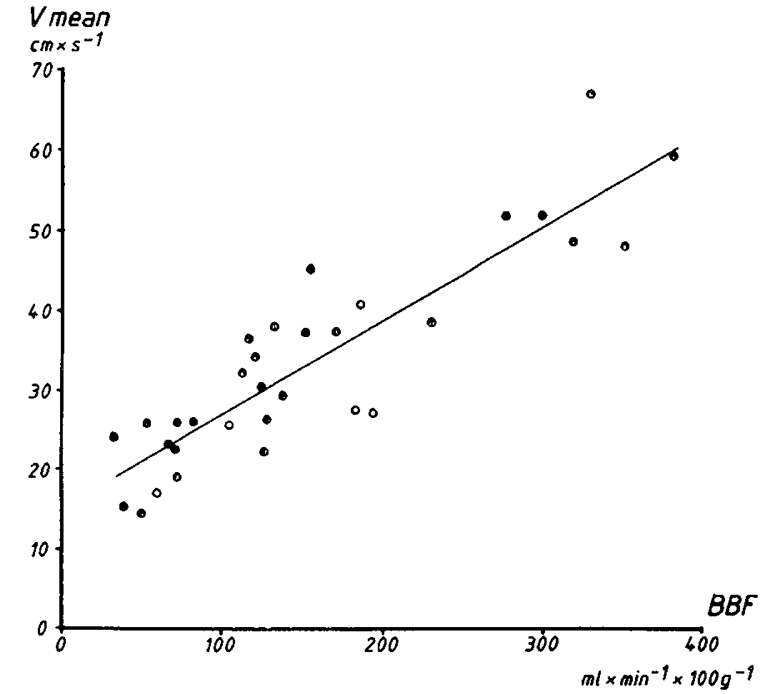

Fig. 3. Correlation between Vmean and BBF, $y=33.3+0.12(x-$ 155), $\mathrm{S}_{\mathrm{y} / \mathrm{x}}=6.10, \mathrm{Sb}_{\mathrm{y} / \mathrm{x}}=0.011, r=0.89, p<0.001$. Unfilled symbols denote recordings during a mean arterial pressure decrease of more than $25 \%$ of the control value.

also demonstrated between blood flow velocities and BBF in the 20 to $80 \mathrm{~mm} \mathrm{Hg} \mathrm{PaCO}_{2}$ range; Vmean (Fig. 3), Vsyst, $\mathrm{b}=0.13$ $(0.014)(\mathrm{cm} / \mathrm{s}) /(\mathrm{ml} / \mathrm{min} / 100 \mathrm{~g}), r=0.87, p<0.001$, and Vdiast, $\mathrm{b}=0.10(0.011), r=0.87, p<0.001$. When recordings made during reduced arterial pressure or with a BBF exceeding 200 $\mathrm{ml} / \mathrm{min} / 100 \mathrm{~g}$ were excluded the relationship of $\mathrm{Vmean}$ to $\mathrm{BBF}$ did not change.

Using normocarbia as a point of reference, the slope of the regression line between blood flow velocity (Vmean, Vsyst, Vdiast) and BBF diverged from the line of identity $(p<0.001)$, and it was also calculated that a $100 \%$ change in BBF corresponded to an approximate 55,45 , and $60 \%$ change in Vmean, Vsyst, and Vdiast, respectively. Using the same recordings as for the comparison between $\mathrm{BBF}$ and $\mathrm{PaCO}_{2}$, a divergence of similar magnitude between relative changes in BBF and Vmean (100 versus $60 \%$ ) was demonstrated when these two variables were independently correlated to $\mathrm{PaCO}_{2}$ (Fig. 4).

\section{DISCUSSION}

The range-gated Doppler technique and an analysis of the frequency spectrum across the lumen of the blood vessel permit an accurate measurement of the true flow velocity (13). The ultrasound beam from a $8 \mathrm{~mm}$ crystal will, if properly directed, insonate the entire CSA of the vessel examined. By recording the highest frequency Doppler signal and analyzing the sequence with the highest velocity, we most effectively insonated the entire CSA. If the angle between the ultrasound beam and the blood flow being studied is small, the absolute Doppler frequency shift can be used and small intraindividual variations of the angle of insonation can be disregarded. Under these circumstances, and provided that the CSA of the vessel does not change, blood flow 


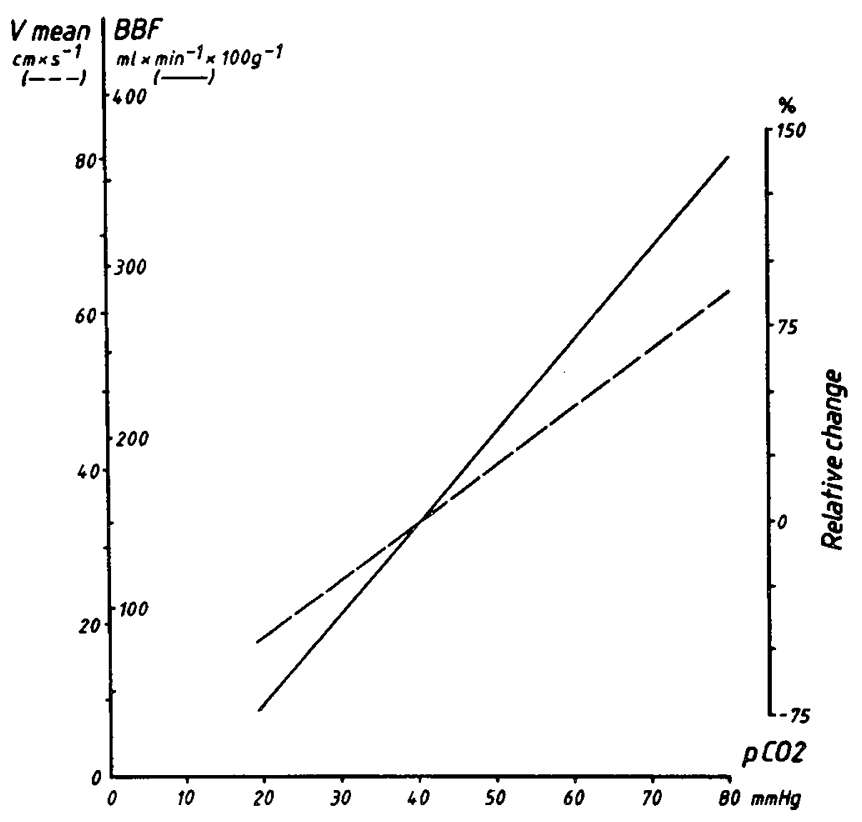

Fig. 4. Regression lines for Vmean (broken line), $\mathrm{y}=33.2+0.74(\mathrm{x}$ -40.0 ), $\mathrm{S}_{\mathrm{y} / \mathrm{x}}=5.69, \mathrm{Sb}_{\mathrm{y} / \mathrm{x}}=0.071, r=0.91, p<0.001$, and $\mathrm{BBF}$ (solid line), $\mathrm{y}=149+5.35(\mathrm{x}-40.0), \mathrm{S}_{\mathrm{y} / \mathrm{x}}=42.1, \mathrm{Sb}_{\mathrm{y} / \mathrm{x}}=0.53, r=0.91, p<$ 0.001 correlated to $\mathrm{PaCO}_{2}(n=23)$. Scales are adjusted to compare relative changes in Vmean and $\mathrm{BBF}$ when $\mathrm{PaCO}_{2}$ is changed from normocarbia $\left(\mathrm{PaCO}_{2}=40 \mathrm{~mm} \mathrm{Hg}\right)$.

velocity changes are directly proportional to changes in $\mathrm{BBF}$. If the angle of insonation is unknown but remains constant between examinations, absolute, but not relative, flow velocity changes are underestimated with increases in the angle.

The present study shows that blood flow velocity and volumetric blood flow, as determined by the microsphere method, change linearly with $\mathrm{PaCO}_{2}$ in the $20-80 \mathrm{~mm} \mathrm{Hg}$ range. In each animal a very close relationship of Vmean to $\mathrm{PaCO}_{2}$ was demonstrated. The absolute and relative response of Vmean to changes in $\mathrm{PaCO}_{2}$ varied between the animals, suggesting an interindividual difference in $\mathrm{PaCO}_{2}$ reactivity. The relative change in Vmean and $\mathrm{BBF} / \mathrm{mm} \mathrm{Hg}$ change of $\mathrm{PaCO}_{2}$ from normocarbia diverged (2.0 versus $3.6 \%)$, suggesting an underestimation of relative $\mathrm{BBF}$ changes by velocity determinations. From the relationship between Vmean and BBF (Fig. 3) it was also calculated that a $100 \%$ change in $\mathrm{BBF}$ corresponds to a $55 \%$ change in Vmean.

A fairly constant angle of insonation during the present experiments was suggested by the moderate difference in Vmean, 1.57 $(1.32) \mathrm{cm} / \mathrm{s}$, before and after microsphere injection. This difference includes both methodological and physiological variations, e.g. an absolute $\mathrm{PaCO}_{2}$ variation of 3.5 (3.4) mm Hg. Hence, a change in the CSA of the vessel being studied seems to contribute to the suggested underestimation of relative changes in BBF with the Doppler technique (Fig. 4).

The method of anesthesia must be considered when interpreting our data. Barbiturates, nitrous oxide, and atropine may influence intracranial vascular tone and reactivity which, in turn, may affect the magnitude of the divergence between blood flow velocity and BBF. However, despite a somewhat higher BBF during normocarbia found in the present study compared to that reported for unanesthetized newborn lambs (14), the vascular reactivity was similar, i.e. the absolute change in $\mathrm{BBF} / \mathrm{mm} \mathrm{Hg}$ of $\mathrm{PaCO}_{2}$.
In a piglet study by Hansen et al. (3) changes in BBF were effected by hyperventilation and carbon dioxide administration, and in a newborn lamb study by Rosenberg et al. (4) BBF changes were induced by hypoxic hypoxia. Both of these studies were performed using a continuous Doppler instrument to measure flow velocities in the anterior cerebral artery. Hansen et al. (3) did not correlate relative changes in blood flow velocity and BBF. In the study by Rosenberg et al. (4) the area under the flow velocity curve, corresponding to Vmean in the present study, predicted about $45 \%$ of the relative change in BBF. Thus, the results of the present study are in agreement with previous observations (4). However, the difference in control BBF found in the two studies, do not allow these percentages to be directly compared.

In conclusion, this study shows that blood flow velocity recorded from a major artery perfusing the brain of the newborn lamb provided qualitative information about changes in $\mathrm{BBF}$ induced by hypo- and hyperventilation. However, the findings also indicate an underestimation of relative changes in BBF with the Doppler technique, probably by means of a concomitant change in the CSA of the vessel being studied. Further investigations are needed to determine if this suggested change in the CSA is a passive phenomenon, caused by changes in volume flow which, in turn, reflect changes in vascular resistance distal to the site of recording, and/or some regulatory mechanism within the artery itself.

These data are not directly applicable to the newborn infant inasmuch as its brain differs from that of the lamb regarding anatomy and arterial supply. Nevertheless, the results of the present study suggest that blood flow velocity is not an accurate quantitative predictor, but can provide qualitative information on changes in BBF in the newborn infant.

\section{REFERENCES}

1. Kirsch JR, Traystman RJ, Rogers MC 1985 Central blood flow measurement techniques in infants and children. Pediatrics 75:887-895

2. Batton DG, Hellman J, Hernandez MJ, Maisels MJ 1983 Regional cerebral blood flow, cerebral blood velocity, and pulsatility index in newborn dogs. Pediatr Res 17:908-912

3. Hansen NB, Stonestreet BS, Rosenkrantz TS, Oh W 1983 Validity of Doppler measurements of anterior cerebral blood flow velocity: correlation with brain blood flow in piglets. Pediatrics 72:526-531

4. Rosenberg AA, Narayanan V, Jones Jr MD 1985 Comparison of anterior cerebral artery blood flow velocity and cerebral blood flow during hypoxia. Pediatr Res 19:67-70

5. Sonesson SE, Lundell BPW, Herin P 1986 Changes in intracranial arterial blood flow velocities during surgical ligation of the patent ductus arteriosus. Acta Paediatr Scand 75:36-42

6. Lundell BPW, Sonesson SE, Cotton RB 1986 Ductus closure in preterm infants. Effects on cerebral hemodynamics. Acta Paediatr Scand [Suppl] 329:140-147

7. Sonesson SE, Winberg P, Lundell BPW 1987 Early postnatal changes in intracranial arterial blood flow velocities in term infants. Pediatr Res 22:461464

8. Dilenge D, Heon M 1974 The internal carotid artery. In: Newton TH, Potts DG (eds) Radiology of the Skull and Brain. CV Mosby Co, New York, pp $1205-1215$

9. Lundell BPW, Kennedy KA, Lindstrom DP, Sundell H, Stahlman MT 1986 Intracranial Doppler flow velocimetry compared with extracranial carotid blood flow measurements. Acta Paediatr Scand [Suppl] 329:127-133

10. Gill RW 1979 Performance of the mean frequency Doppler modulator. Ultrasound Med Biol 5:237-247

11. Heymann MA, Payne BD, Hoffman JI, Rudolph AM 1977 Blood flow measurements with radionuclide-labeled particles. Prog Cardiovasc Dis 20:55-65

12. Buckberg GD, Luck JC, Payne DB, Hoffman JIE, Archie JP, Fixler DE 1971 Some sources of error in measuring regional blood flow with radioactive microspheres. J Appl Physiol 31:598-604

13. Lundell BPW, Lindstrom DP, Arnold TG 1984 Neonatal cerebral blood flow velocity. An in vitro validation of the pulsed Doppler technique. Acta Paediatr Scand 73:810-815

14. Rosenberg AA, Jones Jr MD, Traystman RJ, Simmons MA, Molteni RA 1982 Response of cerebral blood flow to changes in PCO2 in fetal, newborn, and adult sheep. Am J Physiol 242:H862-H866 